\title{
FAKTOR-FAKTOR YANG BERHUBUNGAN DENGAN KEJADIAN HIPERTENSI PADA IBU RUMAH TANGGA DI PUSKEMAS GANG AUT KELURAHAN PALEDANG KECAMATANBOGOR TENGAH KOTA BOGOR TAHUN 2018
}

\author{
Ranisa Andini ${ }^{1)}$, Ichayuen Avianty ${ }^{2)}$, Andreanda Nasution ${ }^{3)}$

\begin{abstract}
${ }^{1)}$ Konsentrasi Kesehatan Ibu dan, Anak, Program Studi Kesehatan Masyarakat, Fakultas Ilmu Kesehatan
${ }^{2)}$ E-mail : ranisaandini13@gmail.com

Program Studi Kesehatan Masyarakat, Fakultas Ilmu Kesehatan Universitas Ibn Khaldun Bogor E-mail : ichayuen@gmail.com

${ }^{3)}$ Program Studi Kesehatan Masyarakat, Fakultas Ilmu Kesehatan Universitas Ibn Khaldun Bogor E-mail : andre.anda@gmail.com
\end{abstract} \\ Universitas Ibn Khaldun Bogor
}

\begin{abstract}
Abstrak
Hipertensi dikenal sebagai tekanan darah tingi yaitu suatu kondisi dimana pembuluh darah terusmenerus mengalami tekanan tinggi. Hipertensi menempati urutan ke 5 penyebab kematian terbanyak di Indonesia menurut (Balitbangkes,2014). Kasus hipertensi di Kota Bogor yaitu sebesar $(0.05 \%)$ terdapat di urutan kedua terbanyak setelah Kota Sukabumi $(0,7 \%)$. Hal ini kota Bogor memiliki kasus hipertensi yang melebihi jumlah rata-rata kasus yaitu sebesar $(0,2 \%)$. (Kemenkes Provinsi Jawa Barat, 2015). Dan Puskemas Gang Aut menduduki peringkat ke 3 yang memiliki angka hipertensi tertinggi di Kota Bogor sebanyak 466 kasus hipertensi pada umur usia produktif (Dinkes,2017). Rancangan penelitian ini menggunakan penelitian kuantitatif menggunakan desain studi cross sectional. Besar sampel dalam penelitian ini sebanyak 115 responden. Data yang di gunakan dalam penelitian ini adalah data primer dan data sekunder. Data primer data yang dikumpulkan melalui kuesioner, sedangkan data sekunder dikumpulkan melalui observasi Kartu Menuju Sehat (KMS), Kesimpulan dalam penelitian ini proporsi ibu rumah tangga yang mengalami hipertensi di Puskemas Gang Aut Kelurahan Paledang sebanyak 79,1\%. Faktor - faktor Yang berhubungan kejadian hipertensi yaitu Genetik sebesar (0,18\%), Stres $(0,41)$. Saran untuk peneliti selanjutnya diharapkan mampu menambah variabel-variabel lain yang kemungkinan berhubungan dengan kejadian hipertensi pada ibu rumah tangga yang tidak ada di penelitian ini.
\end{abstract}

\section{Kata Kunci :Hipertensi. Ibu rumah tangga, Hipertensi pada ibu rumah tangga}

\section{PENDAHULUAN}

Hipertensi merupakan penyakit degeneratif yang menjadi masalah serius pada saat ini. Hipertensi dikategorikan sebagai the silent disease atau the silent killer karena penderita tidak mengetahui dirinya mengidap hipertensi atau tidak mengetahui sebelum memeriksakan tekanan darahnya. Insiden hipertensi meningkat seiring bertambahnya usia.

Hipertensi atau tekanan darah tinggi adalah peningkatan tekanan darah sistolik lebih dari $140 \mathrm{mmHg}$ dan tekanan darah dan tekanan darah sistolik lebih dari $90 \mathrm{mmHg}$ pada dua kali pengukuran dengan selang 
waktu lima menis dalam keadaan cukup atau istirahat/tenang (Kemenkes, 2014) ${ }^{1}$.

Menurut American Heart Association (AHA), penduduk Amerika yang berusia diatas 20 tahun menderita hipertensi telah mencapai angka hingga 74,5 juta jiwa, namun hampir sekitar 90-95\% kasus tidak diketahui penyebabnya (Kemenkes RI, 2014). ${ }^{1}$

Data dari WHO (World Health Organization) pada tahun 2013 menunjukan bahwa terdapat 9,4 juta orang dari 1 milyar penduduk di dunia yang meninggal akibat gangguan sistem kardiovaskular. Prevalensi hipertensi di Negara maju sebesar 35\% dan di Negara berkembang sebesar $40 \%$ dari populasi dewasa. Pada tahun 2025 diperkirakan kasus hipertensi terutama di Negara berkembang akan mengalami peningkatan $80 \%$ menjadi 1,15 milyar kasus. Prediksi ini didasarkan pada angka penderita hipertensi dan bertambahnya penduduk saat ini ${ }^{3}$.

Prevalensi hipertensi di Indonesia tahun 2013 yang di dapat melalui pengukuran pada umur $\geq 18$ tahun sebesar $25,8 \%$. Jumlah prevalensi hipertensi tertinggi berada di Bangka Belitung (30,9\%), terendah berada di Provinsi Papua (16,8\%), sedangkan Jawa

\section{METODE}

Penelitian ini dilakukan dengan pendekatan kuantitatif dengan cross sectional. Penelitian ini adalah jenis penelitian Kuantitatif dengan desain cross sectional,yaitu mempelajari hubungan anatara variabel dependen (Hipertensi) dan variabel Independen (Umur, genetik, aktifitas fisik dan merokok). Melalui pengukuran sesaat atau hanya satu kali saja serta di lakukan dalam waktu bersamaan.

Penelitian dilakukan pada bulan Agustus sampai September 2018 diwilayah kelurahan Paledang, Bogor tengah. Pemilihan lokasi penelitian disebabkan karena
Barat berada di peringkat ke empat hipertensi (29,4\%). (Riskesdas, 2013) .

Pada tahun 2015 di Jawa Barat di temukan 530.387 orang kasus yang terkena hipertensi (0.07 terhadap jumlah penduduk $\geq 18$ tahun), terbesar di 22 Kabupaten / Kota,dan 5 Kabupaten/Kota lainnya. Kasus hipertensi di Kota Bogor yaitu sebesar $(0.05 \%)$ terdapat di urutan kedua terbanyak setelah Kota Sukabumi $(0,7 \%)$. Hal ini kota Bogor memiliki kasus hipertensi yang melebihi jumlah rata-rata kasus yaitu sebesar (0,2\%). (Kemenkes Provinsi Jawa Barat, $2015)^{5}$.

Berdasarkan uraian diatas penulis sangat tertaik untuk mengkaji lebih dalam lagi tentang permasalahan hipertensi. Khususnya di Bogor Bagian Tengah Tepatnya di Puskemas Gang Aut Kelurahan Paledang. Maka dari itu penulis melakukan penelitian dan pembahasan terhadap pokok permasalahan yang diangkat, yang hasilnya di tuangkan dalam suatu tulisan ilmiah dalam bentuk skripsi dengan judul : "Faktor-faktor yang berhubungan dengan kejadian hipertensi pada ibu rumah tanga di puskesmas Gang Aut Kelurahan Paledang Kecamatan Bogor Tengah Kota Bogor Tahun 2018”.

dikelurahan ini masih tingginya angka hipertensi pada kalangan ibu rumah tangga.dibandingkan dengan kelurahan gudang yang berada di kecamatan Bogor tengah.

Populasi adalah wilayah generalisasi yang terdiri ata obyek atau subyek yang mempunyai kuantitas dan karakteristik tertentu yang ditetapkan oleh peneliti untuk dipelajari dan kemudian di tarik kesimpulannya (Sugiyono, 2014) ${ }^{6}$. Populasi dalam penelitian ini adalah seluruh ibu rumah tangga yang terkena hipertensi baik kasus lama maupun baru yang berusia 15-45 tahun, 
yang berada dikelurahan Paledang, Bogor tengah yang berjumlah 221 responden.

Sampel dalam penelitian ini ibu rumah tangga antara usia 15-45 tahun yang berada di kelurahan paledang Kecamatan bogor tengah dengan menggunakan rumus solvin di dapatkan 69 responden untuk meminimalisir kesalahan pada saat turun lapangan peneliti menambah responden sebanyak 46 menjadi 115 responden yang diteliti.

\section{HASIL}

Berdasarkan hasil obeservasi lapangan di Kelurahan Paledang Gambaran umur pada ibu rumah tangga bahwa yang berumur 15-44 tahun lebih banyak yaitu 91 orang $(79,1 \%)$, sedangkan yang berumur 45 tahun sebanyak 24 orang $(20.9 \%)$.

Berdasarkan faktor umur dari 115 responden diperoleh hasil reponden berumur 15-44 tahun lebih banyak yaitu 91 orang $(79,1 \%)$ sedangkan responden yang usianya 45 tahun sebanyak 24 orang (20,9\%). Untuk umur terendah yaitu 22 tahun dan umur tertinggi yaitu 45 tahun.

Berdasarkan faktor Genetik dari 115 responen dapat diketahui bahwa responden yang memiliki riwayat keluarga hipertensi lebih tinggi yaitu sebanyak 75 orang $(65,2 \%)$, sedangkan untuk reponden yang tidak memiliki riwayat keluarga hipertensi sebanayak 40 orang $(34,8 \%)$.

Berdasarkan Faktor Obesitas dari 115 responden dapat diketahui bahwa responden yang tidak mengalami obesitas lebih banyak yaitu 59 orang $(51,3 \%)$. Sedangkan responden
Data yang digunkan dalam penelitian ini adalah data primer dan data sekunder. data primer di peroleh dengan cara memberikan kuesioner dan. menwawancarai ibu rumah tangga di kelurahan paledang. Data sekunder di peroleh dari laporan hasil pelayanan kesehatan Posbindu penyakit tidak menular di Posbindu Kelurahan Paledang Kota Bogor.

yang mengalami obesitas sebanyak 56 orang $(48,7 \%)$.

Berdasarkan Faktor Aktifitas Fisik dari 115 responden yang melakukan aktifitas fisik sebanyak 31 orang $(27,0 \%)$. Dan responedn yang tidak melakukan aktifitas fisik sebanyak 84 orang $(73,0 \%)$. Artinya dapat disimpulkan lebih banyak responden yang tidak melakukan aktifitas fisik dari pada yang beraktifitas fisik.

Berdasarkan Faktor Merokok dari 115 responden yang tidak merokok lebih banyak yaitu sebesar 96 orang $(83,5 \%)$. Sedangkan responden yang merokok sebesar 19 orang $(16,5 \%)$.

Berdasakan Faktor Stres dari 115 responden menunjukan bahwa lebih banyak yang mengalami stress yaitu sebanyak 80 orang $(69,6 \%)$. Sedangkan yang tidak mengalami stress yaitu sebanyak 35 orang $(30,4 \%)$.

Berdasarkan Hasil Bivariat FaktorFaktor yang berhubungan dengan kejadian hipertensi pada ibu rumah tangga di Puskesmas Gang Aut Kelurahan Paledang dapat di lihat sebagai berikut : 
Tabel 1 : Hubungan antara Genetik dengan Kejadian Hipertensi

\begin{tabular}{|c|c|c|c|c|c|c|c|c|}
\hline \multirow{3}{*}{ Genetik } & \multicolumn{4}{|c|}{ Kejadian Hipertensi } & \multirow{2}{*}{\multicolumn{2}{|c|}{ Total }} & \multirow{3}{*}{$\begin{array}{c}\mathbf{P} \\
\text { Value }\end{array}$} & \multirow{3}{*}{$\begin{array}{c}\text { RR } \\
\text { Relati } \\
\text { ve } \\
\text { Risk) }\end{array}$} \\
\hline & \multicolumn{2}{|c|}{$\begin{array}{c}\text { Tidak } \\
\text { Hipertensi }\end{array}$} & \multicolumn{2}{|c|}{ Hipertensi } & & & & \\
\hline & $\mathbf{n}$ & $\%$ & $\mathbf{N}$ & $\%$ & $\mathbf{N}$ & $\%$ & & \\
\hline $\begin{array}{l}\text { Tidak } \\
\text { Ada }\end{array}$ & 15 & 37,5 & 25 & 62,5 & 40 & 100 & & \\
\hline riwayat & & & & & & & & 0,234 \\
\hline $\begin{array}{c}\text { Ada } \\
\text { riwayat }\end{array}$ & 12 & 16,0 & 63 & 84,0 & 75 & 100 & 0,18 & 4 \\
\hline Total & 27 & 23,5 & 88 & 76,5 & 115 & 100 & & \\
\hline
\end{tabular}

Tabel 2 : Hubungan antara Stres dengan Kejadian Hipertensi

\begin{tabular}{|c|c|c|c|c|c|c|c|c|}
\hline \multirow{3}{*}{ Stres } & \multicolumn{4}{|c|}{ Kejadian Hipertensi } & \multirow{2}{*}{\multicolumn{2}{|c|}{ Total }} & \multirow{3}{*}{$\begin{array}{c}\mathbf{P} \\
\text { Value }\end{array}$} & \multirow{3}{*}{$\mathbf{R R}$} \\
\hline & \multicolumn{2}{|c|}{$\begin{array}{c}\text { Tidak } \\
\text { Hipertensi }\end{array}$} & \multicolumn{2}{|c|}{ Hipertensi } & & & & \\
\hline & $\mathbf{n}$ & $\%$ & $\mathbf{n}$ & $\%$ & $\mathbf{N}$ & $\%$ & & \\
\hline $\begin{array}{l}\text { Tidak } \\
\text { Stres }\end{array}$ & 13 & 37,1 & 22 & 62,9 & 35 & 100 & & \\
\hline Stres & 14 & 17,5 & 66 & 82,5 & 80 & 100 & 0,41 & 2,122 \\
\hline Total & 27 & 23,5 & 88 & 76,5 & 115 & 100 & & \\
\hline
\end{tabular}

\section{PEMBAHASAN}

Berdasarkan Tabel 2, menunjukan Hasil uji statistik di peroleh nilai $\mathrm{p}$ value $=0,18$ $(>0,05)$, artinya terdapat hubungan bermakna antara genetik dengan hipertensi. Penelitian ini sejalan dengan hasil penelitian yang dilakukan oleh Sundari $(2015)^{8}$ tentang "Faktor-Faktor yang berhubungan dengan kejadian hipertensi" memperoleh nilai $\mathrm{p}$ value $=0,12 \quad(p>0,05) \quad$ sehingga terdapat hubungan antara riwayat keluarga dengan kejadian hipertensi. Dan sejalan dengan penelitian yang dilakukan oleh Pramana (2016) $)^{9}$ tentang "Faktor-Faktor yang berhubungan dengan Tingkat Hipertensi di Wilayah Kerja Puskesmas Demak II' yang menyatakan adanya hubungan antara riwayat keluarga dengan kejadian hipertensi yang dapat dilihat dari hasil uji statistik ( $\mathrm{p}=0,003$ $<0,05)$.

Berdasarkan Tabel 6, menunjukan Hasil uji statisitik diperoleh nilai $\mathrm{p}$ value $=0,041$
(>0.05) artinya terdapat hubungan antara stres dengan kejadian hipertensi pada ibu rumah tangga. Peneltian Namun penelitian ini tidak sejalan dengan penelitian yang di lakukan oleh Rahayu (2015)"Faktor-Faktor Yang Berhubungan Dengan Kejadian Hipertensi di UPT.Puskesmas Garuda Kota Bandung" dengan hasil uji statistik nilai $\mathrm{p}$ value $=0,060$. $(>0,05)$.

Berdasarkan hasil penelitian ini penulis dapat menyimpulkan bahwa Faktor-faktor yang berhubungan dengan kejadian hipertensi pada ibu rumah tangga di Puskemas Gang Aut Kelurahan Paledang Kecamatan Bogor tengah Kota Bogor yang terkena hipertensi cukup tinggi yaitu sebesar 76,5\% dan untuk yang tidak menderita hipertensi hanya 23,5\%. Dari ke 6 faktor penelitian yang telah dilakukan hanya 2 faktor saja yang berhubungan dalam penelitian ini yaitu Genetik mengahasilkan $p$ value $=0,18$ yang menunjukan bahwa ada 
hubungan yang signifikan antara genetik dengan kejadian hipertensi. Dan faktor stress yang memiliki angka $p$-value $=0,41$

\section{SARAN}

Saran untuk peneliti selanjutnya diharapkan mampu menambah variabelvariabel lain yang kemungkinan berhubungan dengan kejadian hipertensi pada ibu rumah tangga yang tidak ada di penelitian ini. Penggunaan rancangan penelitian yang lebih

\section{DAFTAR PUSTAKA}

[1] Kementerian Kesehatan Republik Indonesia 2014. Infodatin (Pusat Data Dan Informasi Kementerian Kesehatan $R I$ ) Hipertensi. Jakarta Kementerian Kesehatan Republik Indonesia.

[2] DinasKesehatan Kota Bogor, (2017). Profile Kesehatan Kota Bogor. Bogor. Dinas Kesehatan Kota Bogor.

[3] WHO. World health day 2013: calls for Intensiified efforts to prevent and control hypertension. 2013. [cited 19 Febuari 2016] available from: http://www.who.int/workforcealiance/m edia/news/2013/who2013story/en/

[4] Riskesdas. Badan Penelitian dan pengembangan kesehatan kementrian kesehatan RI. 2013. [19 Febuari 2016 ]; Available from: http://www.litbang.depkes.go.id/sites/do wnload/rkd2013/Laporan_Riskesdas201 3.pdf.

[5] Kementerian Kesehatan Republik Indonesia 2014. Infodatin (Pusat Data Dan Informasi Kementerian Kesehatan RI) Hipertensi. Jakarta Kementerian Kesehatan Republik Indonesia

[6] Sugiyono.(2014). Metode Peneltian Kuantitatif. Kualitatif Dan $R \& D . B a n d u n g$.Alfabeta menunjukan bahwa adanya adanya hubungan yang signifikan antara faktor stress dengan kejadian hipertensi pada ibu rumah tangga.

baik seperti studi kohort, atau dengan jumlah sampel yang lebih besar dan membuat kuesioner untuk menentukan diagnosa hipertensi dengan memberikan pertanyaan riwayat hipertensi responden.

[7] Novian,A.(2013). "Faktor yang Berhubungan dengan Keputahan Diet Pasien Hipertensi (Studi pada Pada Pasien Rawat Jalan di Rumah Sakit Islam Sultan Agung Semarang".skripsi.Fakultas Ilmu Keolahragaan. Universitas Negeri Semarang.

[8] Sundari\&Bangsawan.(2015)“FaktorFaktor yang berhubungan dengan kejadian hipertensi'.Jurnal Keperawatan.Volume XI.No.2

[9] Prmana,Dwi,Y,L.(2016) tentang "Faktor-Faktor yang Berhubungan dengan Tingkat Hipertensi di Wilayah Kerja Puskesmas Demak II'.skripsi.Semarang Universitas Muhammadiyah Semarang

[10] Artiyaningrum dan azam (2016). Faktor-faktor yang berhubungan dengan kejadian hipertensi tidak terkendali pada penderita yang melakukan pemeriksaan rutin. Public Health Perspective Journal. Volume 1 No1

[11] Rahayu,Yayu(2015) Faktor-faktor yang berhubungan dengan kejadian hipertensi di UPT Puskesmas Garuda Kota Bandung. Skripsi.Depok FKM UI 